\title{
Evaluation of the Translation, Cross-cultural Adaptation and Properties of Measurement of the FACT-BMT Questionnaire
}

\author{
Thalissa Maniaes ${ }^{1}$, Ana Paula Carraro ${ }^{2}$ and Indiara Soares Oliveira ${ }^{3}$ \\ 1. Master's and Residency Program/Multiprofessional Development in Oncological Physical Therapy, Antonio Prudente Foundation \\ - A.C. Camargo Cancer Center, Rua Antonio Prudente, 211 - Liberdade, São Paulo-SP 01509-010, Brazil \\ 2. Residency Program/Multiprofessional Development in Oncological Physical Therapy, Antonio Prudente Foundation - A.C. \\ Camargo Cancer Center, Rua Antonio Prudente, 211 - Liberdade, São Paulo-SP 01509-010, Brazil
}

3. Master's and PhD Program, Universidade Cidade de São Paulo (Unicid) / A.C. Camargo Cancer Center, Rua Antonio Prudente, 211 - Liberdade, São Paulo-SP 01509-010, Brazil

\begin{abstract}
Various questionnaires have been described which evaluate the quality of life in patients undergoing cancer treatment, but most were originally developed in English and have not been adequately validated for other languages. To evaluate the process of translation and cross-cultural adaptation and the measurement properties of the Functional Assessment of Cancer Therapy-Bone Marrow Transplantation (FACT-BMT) questionnaire, a systematic review was conducted with two independent evaluators. The search for articles was carried out in four databases: MEDLINE, EMBASE, CINAHL and SCIELO, using the terms "questionnaire", "quality of life", "oncology", and "valid" and their descriptors according to MeSH and DeCs. The searches yielded 6,877 studies, of which only three performed the stages of translation, cross-cultural adaptation, and evaluation of the measurement properties of the FACT-BMT questionnaire. The instruments in Arabic, Chinese, Korean and Portuguese showed and presented good methodological quality, but none of the four studies followed all the validation criteria for the questionnaire. The adapted versions of the FACT-BMT have methodological weaknesses in their process of translation and cross-cultural adaptation and evaluation of measurement properties, therefore the questionnaires possibly being used inadequately in other languages.
\end{abstract}

Key words: FACT-BMT, questionnaire, quality of life, translation, cross-cultural adaptation and measurement properties.

\section{Highlights}

- $\quad$ Several questionnaires are available to assess the quality of life.

- $\quad$ The FACT-BMT was developed in the English language and used in different cultures.

- Cross-cultural adaptation should maintain the measurement properties.

- This questionnaire is being used in clinical practice without adequate validation.

\section{Introduction}

The Functional Assessment of Cancer Therapy-Bone Marrow Transplantation (FACT-BMT) is a simple, brief and self-administered questionnaire with 50-item developed in English language which

\footnotetext{
Corresponding author: Thalissa Maniaes, tha_maniaes@yahoo.com.br, Physiotherapist and Master's Degree Student - A.C. Camargo Cancer Center, São Paulo, Brazil.
}

consists of a multidimensional assessment of the functional aspects and quality of life (QoL) of patients submitted to hematopoietic stem cell transplantation (HSCT). This questionnaire is a combination of BMT domain (named as Additional Concerns) added to the FACT-G. The FACT-G is a 27 -item questionnaire of general questions divided into four primary quality of life domains: physical well-being (PWB; 7-items), social/family well-being (SWB; 7-items), emotional 
well-being (EWB; 6-items); and functional well-being (FWB; 7-items). The BMT domain has 23 items, 18 items addressing the BMT related side effects, specifically designed to assess the BMT patients' quality of life [1]. Five other questions from different QoL questionnaire were added in the BMT domain as they were considered relevant to FACT-BMT [1]. The standard treatment for leukemia, lymphoma, and multiple myeloma (MM) is the hematopoietic stem cell transplantation (HSCT) [2, 3], which consists of intravenous infusion of hematopoietic progenitor cells with the objective of restoring marrow function in the patients, replacing the diseased bone marrow [4]. HSCT affects the physical, functional, and emotional well-being of the patient due to several factors such as prolonged hospitalization, isolation, intensive care regimen, morbidity, and high mortality risk [5] due to the immunosuppression induced by the pre-HSCT conditioning regimen. This regimen makes the patient temporarily vulnerable to complications that not only risk their physical integrity, but also their lives, and $40 \%$ of the patients who undergo this therapy show an unfavorable clinical course [6]. HSCT is associated with various psychological, physical, and social challenges that affect the patients' quality of life (QoL) [7-10] and is mainly related to the chronic complications and the family structure of each patient and tends to improve over time [11]. In order to evaluate pain, disability related to treatment, and quality of life, as well as provide a prognosis, collect patient information, and define treatment, health professionals use resources such as the QoL evaluation questionnaires described in the literature, most of which have been originally developed in English [12].

However, since the world's population does not share the same language, culture, or lifestyle, researchers must adapt the original questionnaire so that it is comprehensible and relevant in its new version, while also being faithful to the original when applied in clinical practice in other countries. This process is known as translation and cultural adaptation [12]. The process of cross-cultural adaptation aims to create equivalence between the original questionnaire and that used in another country to maintain validation of the content as well as interchangeability with the original version. An inadequate translation and adaptation process can lead to an instrument that is not equivalent to the original questionnaire $[13,14]$.

Therefore, the aim of this study was to conduct a systematic review to evaluate the methodological quality of the process of translation/cross-cultural adaptation of the FACT-BMT questionnaire [1] into different languages and cultures and of the evaluation of its measurement properties.

\section{Materials and Methods}

\subsection{Search Strategy}

The search was performed in the databases MEDLINE, CINAHL, EMBASE, and BIREME (SCIELO) using the terms "questionnaire", "quality of life", "oncology", and "valid" and their descriptors according to MeSH in English and DeCS in Portuguese (Appendix 1). The last search was performed on 15/08/2018.

\subsection{Inclusion and Exclusion Criteria}

We selected only those studies that used a translated version of the FACT-BMT instrument [1], without restriction of year of publication, exclusively in patients submitted to HSCT. The exclusion criteria were duplicate studies between databases, title and abstracts unrelated to the theme, studies in the original language, and systematic reviews. Conference documents, book chapters, conference proceedings, dissertations, and these were also excluded, as well as studies not found in full or not provided by the authors after contact by e-mail.

\subsection{Data Extraction}

Study selection was carried out by two independent evaluators, who first made the exclusion by reading the titles and abstracts and then by reading the full text. 
After inclusion of the studies, the evaluators extracted the information on translation/cross-cultural adaptation and measurement properties. In case of disagreement among the evaluators, a third evaluator would be consulted, however this was not necessary in this instance.

\subsection{Translation and Cross-cultural Adaptation}

The translation and cross-cultural adaptation process was evaluated in this review according to the guidelines of Beaton et al. [15] and includes (1) translation : two translations of the original document must be carried out by different bilingual translators; (2) synthesis of translation: the two translators and another member synthesize the results of the translations, producing a common translation; (3) backtranslation: two or more translators do a new translation into the instrument's source language, generating a consensus translation; (4) analysis by an expert committee: the aim is to consolidate the versions of the questionnaire and develop the pre-final version; and (5) pre-test of the pre-final version: the pre-final version of the questionnaire is tested and the participants correspond to the target audience of the questionnaire, ensuring that the adapted version is equivalent to the original (Table 1).

\subsection{The Measurement Properties}

The evaluation of the measurement properties of the instrument should be carried out with the purpose of ascertaining its applicability after cross-cultural adaptation, since there are cultural differences between the populations. The present review followed the quality criteria described by Terwee et al. [16], which includes (1) internal consistency: the inter-relationship between the items of a scale or subscale verifying the homogeneity among the various items related to each other using Cronbach's alpha; (2) validity of the construct: the degree to which the scores of an instrument are consistent with the hypotheses; (3) reproducibility (agreement and reliability): the degree to which repeated measures in stable participants provide similar answers; (4) responsiveness: an instrument's ability to detect clinical changes over time of the construct to be measured and the ceiling and floor effects, considered present when more than $15 \%$ of the participants achieve the maximum or minimum scores (Table 2).

Table 1 Description of the methodology for evaluation of the quality criteria of the translation and cross-cultural adaptation of health questionnaires [15-19].

\begin{tabular}{ll}
\hline $\begin{array}{l}\text { Phases of translation and } \\
\text { cross-cultural adaptation }\end{array}$ & Quality criteria used to evaluate the process of translation and cross-cultural adaptation \\
& + Translation by independent translators (two or more); \\
Translation & ? Doubtful process; \\
& - Translation done by only one translator; \\
& 0 The translation process was not reported. \\
& + Synthesis completed; \\
Synthesis of translations & ? Doubtful process; \\
& 0 The process of synthesis of translations was not reported. \\
& + Back translation by independent translators (two or more). \\
& ? Doubtful process. \\
Back translation & - Back translation done by only one translator. \\
& 0 The back-translation process was not reported. \\
& + The presence of an expert committee has been clearly described. \\
Expert committee & ? Doubtful process. \\
& 0 The review process of the expert committee was not reported. \\
& + The pre-test of the pre-final version was carried out in the target population. \\
Test of pre-final version & ? Doubtful process. \\
& 0 The pre-test of the pre-final version was not reported. \\
\hline
\end{tabular}

+ Positive rating; ? Indeterminate rating; - Negative rating; $0=$ No information available. 
Table 2 Description of the methodology for evaluation of the quality of the measurement properties of health questionnaires [16-19].

\begin{tabular}{|c|c|}
\hline Properties & Quality criteria \\
\hline Internal consistency & $\begin{array}{l}\text { + Factorial analyses performed on adequate sample size }(7 \text { participants per item or }>100 \\
\text { participants in total) and Cronbach's alpha(s) calculated per dimension in a sample size of at least } \\
50 \text { patients and Cronbach's alpha(s) between } 0.70 \text { and } 0.95 ; \\
\text { ? No factor analysis or doubtful design or method; } \\
\text { - Cronbach's alpha(s) }<0.70 \text { or }>0.95 \text {, despite adequate design and method; } \\
0 \text { No information on internal consistency. } \\
+75 \% \text { of the results agree with the specific hypotheses formulated; }\end{array}$ \\
\hline Construct validity & $\begin{array}{l}\text { ? Doubtful design or method (no formulation of hypotheses); } \\
-<75 \% \text { of the hypotheses were confirmed, despite adequate design and method; } \\
0 \text { No information on construct validity. }\end{array}$ \\
\hline \multicolumn{2}{|l|}{ Reproducibility } \\
\hline 3.1 Agreement & $\begin{array}{l}\text { + MIC < SDC or MIC outside the LOA or convincing arguments in this criterion are acceptable; } \\
\text { ? Doubtful design or method or no definition of MICs and unconvincing arguments that the } \\
\text { criterion is acceptable; } \\
\text { - MIC > SDC or MIC equal to or within LOA, despite adequate design and method; } \\
0 \text { No information on agreement. }\end{array}$ \\
\hline 3.2 Reliability & $\begin{array}{l}\text { + Moderate ICC or kappa }>0.70 \text {; } \\
\text { ? Doubtful design or method (time interval not mentioned); } \\
\text { - Moderate ICC or kappa of } 0.70 \text {, despite adequate design and method; } \\
0 \text { No information on reliability. }\end{array}$ \\
\hline Responsiveness & $\begin{array}{l}\text { + SDC or SDC }<\text { MIC or MIC outside the LOA or RR }>1.96 \text { or AUC }>0.70 \text {; } \\
\text { ? Doubtful design or method; } \\
\text { - SDC or SDC }>\text { MIC or MIC equal to or within LOA or RR }<1.96 \text { or AUC }<0.70 \text {, despite } \\
\text { adequate design and methods; } \\
0 \text { No information on response capability. }\end{array}$ \\
\hline Floor and ceiling effects & $\begin{array}{l}\text { + Less than } 15 \% \text { of responses achieved the highest or lowest score possible; } \\
\text { ? Doubtful design or method; } \\
\text { - More than } 15 \% \text { of respondents achieved the highest or lowest possible score, although the design } \\
\text { and methods are adequate; } \\
0 \text { No information on ceiling and floor effects. }\end{array}$ \\
\hline \multicolumn{2}{|c|}{$\begin{array}{l}\text { MIC = Minimal important change; SDC = smallest detectable change; LOA = limits of agreement; ICC = intraclass correlation } \\
\text { coefficient; SD = standard deviation. }\end{array}$} \\
\hline
\end{tabular}

\section{Results}

A total of 6,877 studies were selected during the search in the MEDLINE, EMBASE, CINAHL, and SCIELO databases. Of these, 176 studies were duplicates. After reading the titles and abstracts, 17 studies were selected for reading in full, of which only three (Fig. 1) carried out the translation and cross-cultural adaptation of the FACT-BMT questionnaire [1] and provided information on the evaluation of the measurement properties of this questionnaire. The studies found were published between 2002 and 2018.

A manual search was also performed that yielded one study in Japanese, and although this study was eligible, it had to be excluded because it was not possible to read the full text. Contact with the author was attempted through email, without a response.

\subsection{Statistical Analysis}

The demographic and clinical characteristics of the versions of the FACT-BMT questionnaire are listed in Table 3.

Table 4 shows the four selected studies that carried out the translation and cross-cultural adaptation of the FACT-BMT [1] questionnaire on quality of life after bone marrow transplantation into Chinese [20], Korean [21], Brazilian Portuguese [22] and Arabic [23] published in the years of 2002, 2006, and 2007, 2018 


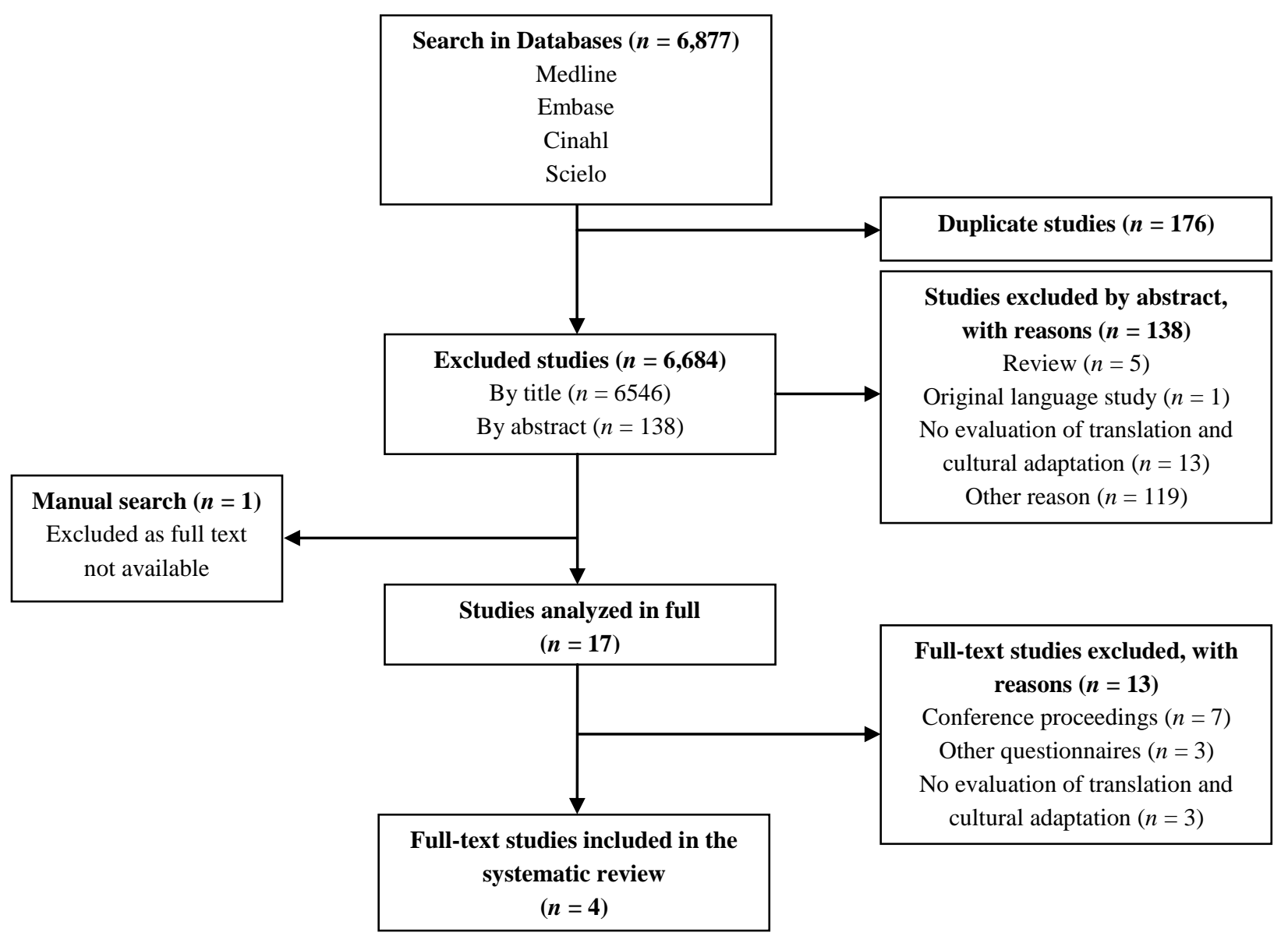

Fig. 1 Flowchart of the selection process of the studies included in the analysis.

Table 3 Demographic and clinical characteristics of the versions of the FACT-BMT questionnaire [20-23].

\begin{tabular}{|c|c|c|c|c|}
\hline Author & $\begin{array}{l}\text { Year of } \\
\text { publication }\end{array}$ & Objective & Population & Socio-demographic characteristics \\
\hline Lau et al. [20] & 2002 & $\begin{array}{l}\text { To evaluate the } \\
\text { psychometric properties of } \\
\text { the traditional Chinese } \\
\text { translation (TCHI) of the } \\
\text { FACT-BMT Version } 4 .\end{array}$ & $\begin{array}{l}134 \text { BMT patients in Hong } \\
\text { Kong. The diagnoses in the } \\
\text { study sample were mixed, } \\
\text { and included acute } \\
\text { leukaemia }(n=52) \text {, chronic } \\
\text { leukaemia }(n=47) \text {, } \\
\text { lymphoma }(n=19) \text {, and } \\
\text { others }(n=16)\end{array}$ & $\begin{array}{l}\text { The median time since BMT was } \\
4.0 \text { years, with a range from } 1.1 \text { to } \\
9.8 \text { years. Of the patients, } 69.4 \% \\
\text { were aged between } 31 \text { and } 50 \text {. Of } \\
\text { these, } 60.5 \% \text { had been educated to } \\
\text { secondary school level, and } 21.6 \% \\
\text { had reached tertiary level or above; } \\
62.7 \% \text { had no religious background. }\end{array}$ \\
\hline Yoo et al. [21] & 2006 & $\begin{array}{l}\text { To translate and cross } \\
\text { culturally adapt the } \\
\text { FACT-BMT scale Version } \\
4 .\end{array}$ & 70 allogeneic BMT patients & $\begin{array}{l}34 \text { males }(48.5 \%) \text { and } 36 \text { females } \\
(51.4 \%) \text { with a median age of } 20-29 \\
\text { years old. }\end{array}$ \\
\hline Mastropietro et al. [22] & 2007 & $\begin{array}{l}\text { To translate into Portuguese } \\
\text { and validate the FACT-BMT } \\
\text { quality-of-life questionnaire, } \\
\text { among bone marrow } \\
\text { transplantation patients. }\end{array}$ & $\begin{array}{l}55 \text { consecutive leukemia } \\
\text { patients }\end{array}$ & $\begin{array}{l}\text { The patients' mean age was } 34.8 \pm \\
8.1 \text { years and mean schooling was } \\
10.8 \pm 4.7 \text { years, and } 78.1 \% \text { of the } \\
\text { patients were female. The mean } \\
\text { time since transplantation was } 29.8 \\
\pm 32.19 \text { months. }\end{array}$ \\
\hline Soudy et al. [23] & 2018 & $\begin{array}{l}\text { To translate and validate } \\
\text { FACT-BMT (Version 4) in } \\
\text { Arabic and report QoL. }\end{array}$ & 108 lymphoma patients & $\begin{array}{l}68 \text { males }(63 \%) \text { and } 40 \text { females } \\
(37 \%) \text { with a median age of } 29 \text { years } \\
\text { (range 14-62). }\end{array}$ \\
\hline
\end{tabular}

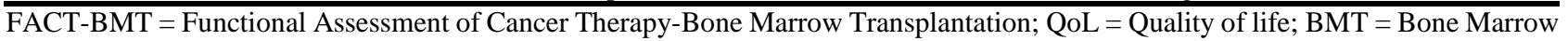
Transplantation. 
Table 4 Evaluation of the versions of the FACT-BMT questionnaire, based on the guidelines for the translation and cross-cultural adaptation process $[15,17-19]$.

\begin{tabular}{llllllll}
\hline Studies & $\begin{array}{l}\text { Year of } \\
\text { publication }\end{array}$ & $\begin{array}{l}\text { Language of } \\
\text { the new } \\
\text { versions }\end{array}$ & Translation & $\begin{array}{l}\text { Synthesis of } \\
\text { translation }\end{array}$ & $\begin{array}{l}\text { Back } \\
\text { translation }\end{array}$ & $\begin{array}{l}\text { Expert } \\
\text { committee } \\
\text { review }\end{array}$ & $\begin{array}{l}\text { Pre-test of the } \\
\text { pre-final } \\
\text { version }\end{array}$ \\
\hline Lau et al. [20] & 2002 & Chinese & + & + & + & + & + \\
Yoo et al. [21] & 2006 & Korean & $?$ & 0 & 0 & 0 & + \\
Mastropietro et al. [22] 2007 & Portuguese & + & + & + & + & + \\
\multicolumn{2}{l}{ Soudy et al. [23] } & 2018 & Arabic & + & + & + & + \\
\hline
\end{tabular}

Table 5 Evaluation of quality of life questionnaires after bone marrow transplant treatment, based on the measurement properties described by Terwee et al. [16-19].

\begin{tabular}{llllllll}
\hline Studies & $\begin{array}{l}\text { Year of } \\
\text { publication }\end{array}$ & $\begin{array}{l}\text { Internal } \\
\text { consistency }\end{array}$ & $\begin{array}{l}\text { Construct } \\
\text { validity }\end{array}$ & $\begin{array}{l}\text { Reproducibility } \\
\text { reliability }\end{array}$ & $\begin{array}{l}\text { Reproducibility/ } \\
\text { Agreement }\end{array}$ & Responsiveness & $\begin{array}{l}\text { Ceiling and } \\
\text { floor effects }\end{array}$ \\
\hline Lau et al. [20] & 2002 & + & $?$ & - & 0 & 0 & 0 \\
Yoo et al. [21] & 2006 & $?$ & $?$ & $?$ & 0 & 0 & 0 \\
Mastropietro et al. [22] & 2007 & $?$ & $?$ & + & 0 & 0 & 0 \\
Soudy et al. [23] & 2018 & + & $?$ & 0 & 0 & 0 & 0 \\
\hline
\end{tabular}

respectively. The Brazilian study [22] carried out the validation of version 3 [24] of the FACT-BMT [1], while the Chinese, Korean and Arabic studies validated version 4 [25] of the FACT-BMT [1].

An analysis of the new versions of the FACT-BMT [1] questionnaire showed that the questionnaires developed in Arabic, Brazilian Portuguese and Chinese followed all stages of the translation and cross-cultural adaptation process. Regarding the stages, the pre-test of the pre-final version was the most tested step. Only the Korean version did not present information on the process of translation synthesis, back translation, and review by expert committee and did not describe the translation process, making this stage doubtful.

Table 5 describes the evaluation of the measurement properties according to the guidelines followed [16]. None of the authors followed all the suggested criteria and did not evaluate reproducibility and agreement, responsiveness, and ceiling and floor effects. In the construct validity criterion, all four studies were doubtful as to their hypotheses. Regarding internal consistency, only the Korean and Arabic studies [21, 23 ] received a positive rating in their evaluation, with inter-relationship between the items of the questionnaire. Regarding reproducibility and reliability, the Korean study [21] did not achieve an adequate intraclass correlation coefficient (Kappa < 0.70). Only the Brazilian Portuguese version showed Kappa $>0.70$ [22].

\section{Discussion}

The purpose of this study was to investigate the methodological quality related to the process of translation, cross-cultural adaptation, and clinimetric testing of the FACT-BMT questionnaire [1] that assesses the quality of life of patients submitted to bone marrow transplantation, following the guidelines proposed and updated by Beaton et al. [15] and Terwee et al. [16]. The cross-cultural adaptation questionnaire for use in a new country, culture, and/or language necessitates use of a unique method, to reach equivalence between the original source and target versions of the questionnaire, the items must not only be translated well linguistically, but also must be adapted culturally to maintain the content validity of the instrument at a conceptual level across different cultures. Attention to this level of detail allows increased confidence that the impact of a disease or its treatment is described in a similar manner in multinational trials or outcome evaluations [1]. The present review showed that there are methodological weaknesses in the validation of the FACT-BMT questionnaire [1] in other languages.

According to the FACIT quality-of-life assessment 
system [26], the FACT-BMT [1] is available in 23 languages (Arabic, traditional Chinese, simplified Chinese, Danish, Dutch, Finnish, French, German, Greek, Hungarian, Italian, Japanese, Korean, Lithuanian, Norwegian, Polish, Portuguese, Romanian, Russian, Spanish, Swedish, Thai, and Turkish), however, during our systematic search, only four studies were found. The authors of the Chinese and Arabic studies [20, 23] even mention that the FACT-BMT questionnaire [1] has been translated and validated into Spanish [27], Dutch [28], French [28], German [28], Italian [28], Norwegian [28], Swedish [28], Japanese [25], Portuguese [25], and Russian [25]. However, when we verified the references, they did not specifically identify validation studies of the FACT-BMT questionnaire [1], but of other questionnaires such as the FACT-G [24] and the FACIT [26].

Another difference found between the studies was that the Arabic, Korean and Chinese studies carried out the translation and cross-cultural adaptation of version 4 [25], that is, the most updated version of the questionnaire, while the Brazilian study used version 3 [24], the oldest version. The most updated version of FACT-BMT was published in 2002, so the Brazilian study [24] should have carried out the validation for the Portuguese language of the most updated version of the questionnaire. The Chinese study [20] also compared the alpha coefficient of version $3(\alpha=0.88)$ to version 4 , showing that the new version has a higher coefficient $(\alpha=0.90)$.

Regarding the translation, the Arabic, Chinese and Brazilian Portuguese studies described the entire methodological process, leaving no doubt about the process. In contrast, the Korean study mentioned the translation process but did not provide detailed information on it, leaving doubt about the process. Furthermore, it did not provide information on the stages translation synthesis, back translation, and expert committee review. The only stage described in this study was the pre-test of the pre-final version [21].
The guidelines for translation and cross-cultural adaptation were published in 2000 [15], serving as a model for this process. Regarding the year of publication, all three studies were published after 2000 , therefore after the guidelines had been published, showing that the Korean study did not follow all the guidelines available in the literature [15].

In relation to the measurement properties of the studies [20-23], the Brazilian study [22] evaluated the criterion construct validity as satisfactory and statistically significant but did not describe the item "hypothesis testing" in its methods, thereby contradicting itself. Regarding internal consistency, the validation to Brazilian Portuguese [22] and Korean [21] was doubtful because, despite an adequate Cronbach's alpha between 0.70 and 0.95 , the sample size was less than 100 patients. In the Chinese study [20], the internal consistency was positive with an adequate sample of 134 patients and Cronbach's alpha > 0.78 and in the Arabic study the sample it was 108 patients with Cronbach's alpha > 0.70 [23].

Regarding the Brazilian Portuguese version [22], the only criterion that was positive was reproducibility/reliability, with a significant correlation coefficient between 0.80 and 0.88 . The Chinese study [20] did not provide the intraclass correlation coefficient, therefore it was classified as inadequate. The Korean study [21] did not explain in detail the method used to test the reliability, leaving doubts about its validation.

The study [16] used as a reference for evaluation of measurement properties was published in 2007, which may justify the methodological weaknesses in the evaluation of all the suggested criteria, as all three studies selected in this review were published before that date, therefore the Arabic study should have followed all the steps of validation of the properties of measures already consolidated in the literature. A limitation of the Brazilian study [22] was the educational level of the sample (23.6\% of the patients), which required a second person to perform the 
interview and fill in the questionnaire thus decreasing the methodological quality. In the Chinese study [20], however, the patients answered the questionnaire themselves without any help and all had secondary education or higher.

The present review was based on the guidelines of Beaton et al. [15] and Terwee et al. [16] to demonstrate the importance of evaluating the translation/cross-cultural adaptation and measurement properties of the FACT-BMT questionnaire [1] for its adequate use in clinical practice in other languages. However, the analysis of the studies showed a lack of methodological quality in the validation of the cross-cultural adaptation of this instrument. Therefore, high-quality studies are needed to adequately validate the FACT-BMT questionnaire [1] in other languages and ensure that the new versions are faithful to the original and can be applied consistently.

\section{Conclusions}

We conclude that the criteria used by the three studies found in our search to evaluate the translation/cross-cultural adaptation and the measurement properties of the FACT-BMT questionnaire [1] are methodologically weak and their reliability is doubtful. Moreover, this questionnaire is possibly being used in clinical practice without adequate validation in other languages and it may not be evaluating what it was designed to evaluate. Future studies are needed to adequately validate the measurement properties of the FACT-BMT questionnaire [1] in other languages.

\section{References}

[1] McQuellon, R. P., Russell, G. B., Cella, D. F., Craven, B. L., Brady, M., Bonomi, A., and Hurd, D. D. 1997. "Quality of Life Measurement in Bone Marrow Transplantation: Development of the Functional Assessment of Cancer Therapy-Bone Marrow Transplant (FACT-BMT) Scale.” Bone Marrow Transplant 19 (4): 357-68.

[2] Copelan, E. A. 2006. "Hematopoietic Stem-Cell Transplantation.” N Engl J Med. 354 (17): 1813-26.
[3] Ljungman, P., Bregni, M., Brune, M., Cornelissen, J., de Witte, T., Dini, G., Einsele, H., Gaspar, H. B., Gratwohl, A., Passweg, J., Peters, C., Rocha, V., Saccardi, R., Schouten, H., Sureda, A., Tichelli, A., Velardi, A., and Niederwieser, D. 2010. "Allogeneic and Autologous Transplantation for Haematological Diseases, Solid Tumours and Immune Disorders: Current Practice in Europe 2009.” Bone Marrow Transplant 45 (2): 219-34.

[4] Armitage, J. O. 1994. "Bone Marrow Transplantation." $N$ Engl J Med. 330 (12): 827-38.

[5] Deeg, H. J. 1990. "Delayed Complications and Long-Term Effects after Bone Marrow Transplantation." Hematol Oncol Clin North Am. 4 (3): 641-57.

[6] Tabak, D. G. 2000. "Transplante de medula óssea na leucemia mielóide crônica." Medicina 33: 232-40.

[7] Fife, B. L., Huster, G. A., Cornetta, K. G., Kennedy, V. N., Akard, L. P., and Broun, E. R. 2000. "Longitudinal Study of Adaptation to the Stress of Bone Marrow Transplantation." J Clin Oncol. 18 (7): 1539-49.

[8] Zittoun, R., Suciu, S., Watson, M., Solbu, G., Muus, P., Mandelli, F., Stryckmans, P., Peetermans, M., Thaler, J., Resegotti, L., Dardenne, M., and Willemze, R. 1997. "Quality of Life in Patients with Acute Myelogenous Leukemia in Prolonged First Complete Remission after Bone Marrow Transplantation (Allogeneic or Autologous) or Chemotherapy: A Cross-sectional Study of the EORTC-GIMEMA AML 8A Trial." Bone Marrow Transplant 20 (4): 307-15.

[9] Grulke, N., Albani, C., and Bailer, H. 2012. "Quality of Life in Patients before and after Haematopoietic Stem Cell Transplantation Measured with the European Organization for Research and Treatment of Cancer (EORTC) Quality of Life Core Questionnaire QLQ-C30." Bone Marrow Transplant 47 (4): 473-82.

[10] Mosher, C. E., DuHamel, K. N., Rini, C., Corner, G., Lam, J., and Redd, W. H. 2011. "Quality of Life Concerns and Depression among Hematopoietic Stem Cell Transplant Survivors." Support Care Cancer 19 (9): 1357-65.

[11] Barrera, M., Boyd-Pringle, L. A., Sumbler, K., and Saunders, F. 2000. "Quality of Life and Behavioral Adjustment after Pediatric Bone Marrow Transplantation." Bone Marrow Transplant 26: 427-35.

[12] Maher, C. G., Latimer, J., and Costa, L. O. P. 2007. "The Relevance of Cross-cultural Adaptation and Clinimetrics for Physical Therapy Instruments." Rev Bras Fisioterap. 11 (4): 245-52.

[13] Herdman, M., Fox-Rushby, J., and Badia, X. 1998. “A Model of Equivalence in the Cultural Adaptation of HRQoL Instruments: The Universalist Approach." Qual Life Res. 7 (4): 323-35.

[14] Guillemin, F., Bombardier, C., and Beaton, D. 1993. "Cross-cultural Adaptation of Health-Related Quality of 
Life Measures: Literature Review and Proposed Guidelines." J Clin Epidemiol 46 (12): 1417-32.

[15] Beaton, D. E., Bombardier, C., Guillemin, F., and Ferraz, M. B. 2000. "Guidelines for the Process of Cross-cultural Adaptation of Self-report Measures." Spine (Phila Pa 1976) 25 (24): 3186-91.

[16] Terwee, C. B., Bot, S. D., de Boer, M. R., van der Windt, D. A., Knol, D. L., Dekker, J., Bouter, L. M., and de Vet, H. C. 2007. "Quality Criteria Were Proposed for Measurement Properties of Health Status Questionnaires." J Clin Epidemiol 60 (1): 34-42.

[17] Da Menezes Costa, L. C., Maher, C. G., McAuley, J. H., and Costa, L. O. 2009. "Systematic Review of Cross-cultural Adaptations of McGill Pain Questionnaire Reveals a Paucity of Clinimetric Testing." Journal of Clinical Epidemiology 62 (9): 934-43.

[18] Puga, V. O. O., Lopes, A. D., and Costa, L. O. P. 2012. Assessment of Cross-Cultural Adaptations and Measurement Properties of Self-report Outcome Measures Relevantto Shoulder Disability in Portuguese: A Systematic Review." Revista Brasileira de Fisioterapia 16 (2): 85-93.

[19] Oliveira, I. S., Costa, L. D. C. M., Fagundes, F. R. C., and Cabral, C. M. N. 2015. "Evaluation of Cross-cultural Adaptation and Measurement Properties of Breast Cancer-Specific Quality-of-Life Questionnaires: A Systematic Review.” Qual Life Res 24: 1179-95.

[20] Lau, A. K., Chang, C. H., Tai, J. W., Eremenco, S., Liang, R., Lie, A. K., Fong, D. Y., and Lau, C. M. 2002. "Translation and Validation of the Functional Assessment of Cancer Therapy-Bone Marrow Transplant (FACT-BMT) Version 4 Quality of Life Instrument into Traditional Chinese." Bone Marrow Transplant 29 (1): 41-9.

[21] Yoo, H., Lee, K., Lee, J., Eremenco, S., Choi, S., and Kim, H. 2006. "Korean Translation and Validity of FACT-BMT Version 4 and the Quality of Life in Allogeneic Bone Marrow Transplantation Patients." Qual Life Res 15 (3):
559-64.

[22] Mastropietro, A. P., Oliveira, E. A., Santos, M. A., and Voltarelli, J. C. 2007. "Functional Assessment of Cancer Therapy Bone Marrow Transplantation: tradução e validação." Rev Saude Publica 41 (2): 260-8.

[23] Soudy, H., Maghfoor, I., Elhassan, T. A. M., Abdullah, E., Rauf, F. M., Zahrani, A. A., and Akhtar, S. 2018. "Translation and Validation of the Functional Assessment of Cancer Therapy-Bone Marrow Transplant (FACT-BMT) Version 4 Quality of Life Instrument into Arabic Language." Health and Quality of Life Outcomes 16: 47.

[24] Cella, D. F., Tulsky, D. S., Gray, G., Sarafian, B., Linn, E., Bonomi, A., Silberman, M., Yellen, S. B., Winicour, P., Brannon, J., et al. 1993. "The Functional Assessment of Cancer Therapy Scale: Development and Validation of the General Measure." J Clin Oncol 11 (3): 570-9.

[25] Cella, D. F. 1997. "Functional Assessment of Chronic Illness Therapy (FACIT) Measurement System Manual Version 4." Center on Outcomes, Research and Education (CORE): Evanston Northwestern Healthcare and Northwestern University, IL.

[26] Webster, K., Cella, D., and Yost, K. 2003. "The Functional Assessment of Chronic Illness Therapy (FACIT) Measurement System: Properties, Applications, and Interpretation." Health Qual Life Outcomes 1: 79.

[27] Cella, D., Hernandez, L., Bonomi, A. E., Corona, M., Vaquero, M., Shiomoto, G., and Baez, L. 1998. "Spanish Language Translation and Initial Validation of the Functional Assessment of Cancer Therapy Quality-of-Life Instrument." Med Care 36 (9): 1407-18.

[28] Bonomi, A. E., Cella, D. F., Hahn, E. A., Bjordal, K., Sperner-Unterweger, B., Gangeri, L., Bergman, B., Willems-Groot, J., Hanquet, P., and Zittoun, R. 1996. "Multilingual Translation of the Functional Assessment of Cancer Therapy (FACT) Quality of Life Measurement System." Qual Life Res. 5 (3): 309-20. 


\section{Appendix}

Appendix 1: Search strategy in the databases.

\begin{tabular}{|c|c|}
\hline \multicolumn{2}{|c|}{ Medline } \\
\hline 1 & $\begin{array}{l}\text { Questionnair\$.mp. [mp=title, abstract, original title, name of substance word, subject heading word, protocol supplementary } \\
\text { concept, rare disease supplementary concept, unique identifier] }\end{array}$ \\
\hline 2 & $\begin{array}{l}\text { Questionnaire Design.mp. [mp=title, abstract, original title, name of substance word, subject heading word, protocol } \\
\text { supplementary concept, rare disease supplementary concept, unique identifier] }\end{array}$ \\
\hline 3 & $\begin{array}{l}\text { Design, Questionnair\$.mp. [mp=title, abstract, original title, name of substance word, subject heading word, protocol } \\
\text { supplementary concept, rare disease supplementary concept, unique identifier] }\end{array}$ \\
\hline 4 & $\begin{array}{l}\text { Designs, Questionnaire.mp. [mp=title, abstract, original title, name of substance word, subject heading word, protocol } \\
\text { supplementary concept, rare disease supplementary concept, unique identifier] }\end{array}$ \\
\hline 5 & $\begin{array}{l}\text { Questionnaire Designs.mp. [mp=title, abstract, original title, name of substance word, subject heading word, protocol } \\
\text { supplementary concept, rare disease supplementary concept, unique identifier] }\end{array}$ \\
\hline 6 & $\begin{array}{l}\text { Instrument\$.mp. [mp=title, abstract, original title, name of substance word, subject heading word, protocol supplementary } \\
\text { concept, rare disease supplementary concept, unique identifier] }\end{array}$ \\
\hline 7 & $\begin{array}{l}\text { Scale\$.mp. [mp=title, abstract, original title, name of substance word, subject heading word, protocol supplementary } \\
\text { concept, rare disease supplementary concept, unique identifier] }\end{array}$ \\
\hline 8 & $\begin{array}{l}\text { Index.mp. [mp=title, abstract, original title, name of substance word, subject heading word, protocol supplementary } \\
\text { concept, rare disease supplementary concept, unique identifier] }\end{array}$ \\
\hline 9 & $\begin{array}{l}\text { Score.mp. [mp=title, abstract, original title, name of substance word, subject heading word, protocol supplementary } \\
\text { concept, rare disease supplementary concept, unique identifier] }\end{array}$ \\
\hline 10 & $\begin{array}{l}\text { Inventory.mp. [mp=title, abstract, original title, name of substance word, subject heading word, protocol supplementary } \\
\text { concept, rare disease supplementary concept, unique identifier] }\end{array}$ \\
\hline 11 & $\begin{array}{l}\text { Evaluat\$.mp. [mp=title, abstract, original title, name of substance word, subject heading word, protocol supplementary } \\
\text { concept, rare disease supplementary concept, unique identifier] }\end{array}$ \\
\hline 12 & $\begin{array}{l}\text { Assess } \$ . m p . ~[m p=t i t l e, \text { abstract, original title, name of substance word, subject heading word, protocol supplementary } \\
\text { concept, rare disease supplementary concept, unique identifier] }\end{array}$ \\
\hline 13 & $\begin{array}{l}\text { Self Report.mp. [mp=title, abstract, original title, name of substance word, subject heading word, protocol supplementary } \\
\text { concept, rare disease supplementary concept, unique identifier] }\end{array}$ \\
\hline 14 & $\begin{array}{l}\text { Self-Report.mp. [mp=title, abstract, original title, name of substance word, subject heading word, protocol supplementary } \\
\text { concept, rare disease supplementary concept, unique identifier] }\end{array}$ \\
\hline 15 & $\begin{array}{l}\text { Report, Self.mp. [mp=title, abstract, original title, name of substance word, subject heading word, protocol supplementary } \\
\text { concept, rare disease supplementary concept, unique identifier] }\end{array}$ \\
\hline 16 & $\begin{array}{l}\text { Reports, Self.mp. [mp=title, abstract, original title, name of substance word, subject heading word, protocol supplementary } \\
\text { concept, rare disease supplementary concept, unique identifier] }\end{array}$ \\
\hline 17 & $\begin{array}{l}\text { Self Reports.mp. [mp=title, abstract, original title, name of substance word, subject heading word, protocol supplementary } \\
\text { concept, rare disease supplementary concept, unique identifier] }\end{array}$ \\
\hline 18 & $\begin{array}{l}\text { Self-Reports.mp. [mp=title, abstract, original title, name of substance word, subject heading word, protocol supplementary } \\
\text { concept, rare disease supplementary concept, unique identifier] }\end{array}$ \\
\hline 19 & $\begin{array}{l}\text { Protocol.mp. [mp=title, abstract, original title, name of substance word, subject heading word, protocol supplementary } \\
\text { concept, rare disease supplementary concept, unique identifier] }\end{array}$ \\
\hline 20 & 1 or 2 or 3 or 4 or 5 or 6 or 7 or 8 or 9 or 10 or 11 or 12 or 13 or 14 or 15 or 16 or 17 or 18 or 19 \\
\hline 21 & $\begin{array}{l}\text { Quality of Life.mp. [mp=title, abstract, original title, name of substance word, subject heading word, protocol } \\
\text { supplementary concept, rare disease supplementary concept, unique identifier] }\end{array}$ \\
\hline 22 & $\begin{array}{l}\text { Quality-of-life.mp. [mp=title, abstract, original title, name of substance word, subject heading word, protocol } \\
\text { supplementary concept, rare disease supplementary concept, unique identifier] }\end{array}$ \\
\hline 23 & $\begin{array}{l}\text { QOL.mp. [mp=title, abstract, original title, name of substance word, subject heading word, protocol supplementary concept, } \\
\text { rare disease supplementary concept, unique identifier] }\end{array}$ \\
\hline 24 & $\begin{array}{l}\text { Karnofsky Performance Status.mp. [mp=title, abstract, original title, name of substance word, subject heading word, } \\
\text { protocol supplementary concept, rare disease supplementary concept, unique identifier] }\end{array}$ \\
\hline 25 & $\begin{array}{l}\text { Life Style.mp. [mp=title, abstract, original title, name of substance word, subject heading word, protocol supplementary } \\
\text { concept, rare disease supplementary concept, unique identifier] }\end{array}$ \\
\hline 26 & $\begin{array}{l}\text { Sickness Impact Profile.mp. [mp=title, abstract, original title, name of substance word, subject heading word, protocol } \\
\text { supplementary concept, rare disease supplementary concept, unique identifier] }\end{array}$ \\
\hline 27 & $\begin{array}{l}\text { Value of Life.mp. [mp=title, abstract, original title, name of substance word, subject heading word, protocol supplementary } \\
\text { concept, rare disease supplementary concept, unique identifier] }\end{array}$ \\
\hline 28 & 21 or 22 or 23 or 24 or 25 or 26 or 27 \\
\hline
\end{tabular}



Measurement of the FACT-BMT Questionnaire

\begin{tabular}{|c|c|}
\hline 29 & $\begin{array}{l}\text { Oncology.mp. [mp=title, abstract, original title, name of substance word, subject heading word, protocol supplementary } \\
\text { concept, rare disease supplementary concept, unique identifier] }\end{array}$ \\
\hline 30 & $\begin{array}{l}\text { cancer.mp. [mp=title, abstract, original title, name of substance word, subject heading word, protocol supplementary } \\
\text { concept, rare disease supplementary concept, unique identifier] }\end{array}$ \\
\hline 31 & $\begin{array}{l}\text { Neoplasm, Benign.mp. [mp=title, abstract, original title, name of substance word, subject heading word, protocol } \\
\text { supplementary concept, rare disease supplementary concept, unique identifier] }\end{array}$ \\
\hline 32 & $\begin{array}{l}\text { Neoplasms, Benign.mp. [mp=title, abstract, original title, name of substance word, subject heading word, protocol } \\
\text { supplementary concept, rare disease supplementary concept, unique identifier] }\end{array}$ \\
\hline 33 & $\begin{array}{l}\text { Benign Neoplasms.mp. [mp=title, abstract, original title, name of substance word, subject heading word, protocol } \\
\text { supplementary concept, rare disease supplementary concept, unique identifier] }\end{array}$ \\
\hline 34 & $\begin{array}{l}\text { Stem Cell Transplantations.mp. [mp=title, abstract, original title, name of substance word, subject heading word, protocol } \\
\text { supplementary concept, rare disease supplementary concept, unique identifier] }\end{array}$ \\
\hline 35 & $\begin{array}{l}\text { Transplantations, Stem Cell.mp. [mp=title, abstract, original title, name of substance word, subject heading word, protocol } \\
\text { supplementary concept, rare disease supplementary concept, unique identifier] }\end{array}$ \\
\hline 36 & $\begin{array}{l}\text { Transplantation, Stem Cell.mp. [mp=title, abstract, original title, name of substance word, subject heading word, protocol } \\
\text { supplementary concept, rare disease supplementary concept, unique identifier] }\end{array}$ \\
\hline 37 & $\begin{array}{l}\text { Transplantation, Hematopoietic Stem Cell.mp. [mp=title, abstract, original title, name of substance word, subject heading } \\
\text { word, protocol supplementary concept, rare disease supplementary concept, unique identifier] }\end{array}$ \\
\hline 38 & $\begin{array}{l}\text { Stem Cell Transplantation, Hematopoietic.mp. [mp=title, abstract, original title, name of substance word, subject heading } \\
\text { word, protocol supplementary concept, rare disease supplementary concept, unique identifier] }\end{array}$ \\
\hline 39 & $\begin{array}{l}\text { Bone Marrow Transplantation.mp. [mp=title, abstract, original title, name of substance word, subject heading word, } \\
\text { protocol supplementary concept, rare disease supplementary concept, unique identifier] }\end{array}$ \\
\hline 40 & $\begin{array}{l}\text { Bone Marrow Purging.mp. [mp=title, abstract, original title, name of substance word, subject heading word, protocol } \\
\text { supplementary concept, rare disease supplementary concept, unique identifier] }\end{array}$ \\
\hline 41 & $\begin{array}{l}\text { Hematopoietic Stem Cell Mobilization.mp. [mp=title, abstract, original title, name of substance word, subject heading word, } \\
\text { protocol supplementary concept, rare disease supplementary concept, unique identifier] }\end{array}$ \\
\hline 42 & $\begin{array}{l}\text { Progenitor Cells, Hematopoietic.mp. [mp=title, abstract, original title, name of substance word, subject heading word, } \\
\text { protocol supplementary concept, rare disease supplementary concept, unique identifier] }\end{array}$ \\
\hline 43 & $\begin{array}{l}\text { Hematopoietic Progenitor Cells.mp. [mp=title, abstract, original title, name of substance word, subject heading word, } \\
\text { protocol supplementary concept, rare disease supplementary concept, unique identifier] }\end{array}$ \\
\hline 44 & $\begin{array}{l}\text { Cell, Hematopoietic Progenitor.mp. [mp=title, abstract, original title, name of substance word, subject heading word, } \\
\text { protocol supplementary concept, rare disease supplementary concept, unique identifier] }\end{array}$ \\
\hline 45 & $\begin{array}{l}\text { Cells, Hematopoietic Progenitor.mp. [mp=title, abstract, original title, name of substance word, subject heading word, } \\
\text { protocol supplementary concept, rare disease supplementary concept, unique identifier] }\end{array}$ \\
\hline 46 & $\begin{array}{l}\text { Hematopoietic Progenitor Cell.mp. [mp=title, abstract, original title, name of substance word, subject heading word, } \\
\text { protocol supplementary concept, rare disease supplementary concept, unique identifier] }\end{array}$ \\
\hline 47 & $\begin{array}{l}\text { Progenitor Cell, Hematopoietic.mp. [mp=title, abstract, original title, name of substance word, subject heading word, } \\
\text { protocol supplementary concept, rare disease supplementary concept, unique identifier] }\end{array}$ \\
\hline 48 & $\begin{array}{l}\text { Stem Cells, Hematopoietic.mp. [mp=title, abstract, original title, name of substance word, subject heading word, protocol } \\
\text { supplementary concept, rare disease supplementary concept, unique identifier] }\end{array}$ \\
\hline 49 & $\begin{array}{l}\text { Cell, Hematopoietic Stem.mp. [mp=title, abstract, original title, name of substance word, subject heading word, protocol } \\
\text { supplementary concept, rare disease supplementary concept, unique identifier] }\end{array}$ \\
\hline 50 & $\begin{array}{l}\text { Cells, Hematopoietic Stem.mp. [mp=title, abstract, original title, name of substance word, subject heading word, protocol } \\
\text { supplementary concept, rare disease supplementary concept, unique identifier] }\end{array}$ \\
\hline 51 & $\begin{array}{l}\text { Stem Cell Mobilization.mp. [mp=title, abstract, original title, name of substance word, subject heading word, protocol } \\
\text { supplementary concept, rare disease supplementary concept, unique identifier] }\end{array}$ \\
\hline 52 & $\begin{array}{l}\text { Mobilization, Stem Cell.mp. [mp=title, abstract, original title, name of substance word, subject heading word, protocol } \\
\text { supplementary concept, rare disease supplementary concept, unique identifier] }\end{array}$ \\
\hline 53 & $\begin{array}{l}29 \text { or } 30 \text { or } 31 \text { or } 32 \text { or } 33 \text { or } 34 \text { or } 35 \text { or } 36 \text { or } 37 \text { or } 38 \text { or } 39 \text { or } 40 \text { or } 41 \text { or } 42 \text { or } 43 \text { or } 44 \text { or } 45 \text { or } 46 \text { or } 47 \text { or } 48 \text { or } 49 \text { or } 50 \\
\text { or } 51 \text { or } 52\end{array}$ \\
\hline 54 & (animals not (humans and animals)).sh. \\
\hline 55 & 53 not 54 \\
\hline 56 & 20 and 28 and 55 \\
\hline 57 & $\begin{array}{l}\text { valid\$.mp. [mp=title, abstract, original title, name of substance word, subject heading word, protocol supplementary } \\
\text { concept, rare disease supplementary concept, unique identifier] }\end{array}$ \\
\hline 58 & $\begin{array}{l}\text { translat\$.mp. [mp=title, abstract, original title, name of substance word, subject heading word, protocol supplementary } \\
\text { concept, rare disease supplementary concept, unique identifier] }\end{array}$ \\
\hline 59 & $\begin{array}{l}\text { cross cultural\$.mp. [mp=title, abstract, original title, name of substance word, subject heading word, protocol } \\
\text { supplementary concept, rare disease supplementary concept, unique identifier] }\end{array}$ \\
\hline
\end{tabular}




\begin{tabular}{|l|l|}
\hline 60 & $\begin{array}{l}\text { cross-cultural\$.mp. [mp=title, abstract, original title, name of substance word, subject heading word, protocol } \\
\text { supplementary concept, rare disease supplementary concept, unique identifier] }\end{array}$ \\
\hline 61 & $\begin{array}{l}\text { cross cultural adapt } \$ \mathrm{mp} . \text { [mp=title, abstract, original title, name of substance word, subject heading word, protocol } \\
\text { supplementary concept, rare disease supplementary concept, unique identifier] }\end{array}$ \\
\hline 62 & $\begin{array}{l}\text { cross-cultural adapt } \$ . \mathrm{mp} \text {. [mp=title, abstract, original title, name of substance word, subject heading word, protocol } \\
\text { supplementary concept, rare disease supplementary concept, unique identifier] }\end{array}$ \\
\hline 63 & $\begin{array}{l}\text { version } \$ . \mathrm{mp} \text {. [mp=title, abstract, original title, name of substance word, subject heading word, protocol supplementary } \\
\text { concept, rare disease supplementary concept, unique identifier] }\end{array}$ \\
\hline 64 & 57 or 58 or 59 or 60 or 61 or 62 or 63 \\
\hline 65 & 56 and64 \\
\hline
\end{tabular}

\begin{tabular}{|c|c|}
\hline \multicolumn{2}{|c|}{ Embase } \\
\hline$\# 1$ & questionnair* AND [embase]/lim \\
\hline$\# 2$ & “questionnaire design” AND [embase]/lim \\
\hline \#3 & “design, questionnaire” AND [embase]/lim \\
\hline$\# 4$ & “designs, questionnaire” AND [embase]/lim \\
\hline$\# 5$ & “questionnaire designs” AND [embase]/lim \\
\hline \#6 & instrument* AND [embase]/lim \\
\hline$\# 7$ & scale* AND [embase]/lim \\
\hline$\# 8$ & index AND [embase]/lim \\
\hline$\# 9$ & score AND [embase]/lim \\
\hline$\# 10$ & inventory AND [embase]/lim \\
\hline$\# 11$ & “evaluation"/exp AND [embase]/lim \\
\hline$\# 12$ & “assessment” AND [embase]/lim \\
\hline$\# 13$ & “self report”/exp AND [embase]/lim \\
\hline$\# 14$ & “self-report”/exp AND [embase]/lim \\
\hline$\# 15$ & “report, self” AND [embase]/lim \\
\hline$\# 16$ & “reports, self" AND [embase]/lim \\
\hline$\# 17$ & “self reports” AND [embase]/lim \\
\hline$\# 18$ & “‘self-reports' AND [embase]/lim \\
\hline \#19 & $\begin{array}{l}\# 1 \text { OR \#2 OR \#3 OR \#4 OR \#5 OR \#6 OR \#7 OR \#8 OR \#9 OR \#10 OR \#11 OR \#12 OR \#13 OR \#14 OR \#15 OR \#16 OR } \\
\# 17 \text { OR \#18 }\end{array}$ \\
\hline$\# 20$ & “quality of life"/exp AND [embase]/lim \\
\hline \#21 & “quality-of-life"/exp AND [embase]/lim \\
\hline$\# 22$ & qol AND [embase]/lim \\
\hline$\# 23$ & “karnofsky performance status"/exp AND [embase]/lim \\
\hline$\# 24$ & “life style"/exp AND [embase]/lim \\
\hline$\# 25$ & “sickness impact profile"/exp AND [embase]/lim \\
\hline \#26 & “value of life"/exp AND [embase]/lim \\
\hline \#27 & \#20 OR \#21 OR \#22 OR \#23 OR \#24 OR \#25 OR \#26 \\
\hline \#28 & “oncology”/exp AND [humans]/lim AND [embase]/lim \\
\hline \#29 & “"Stem Cell Transplantations” AND [humans]/lim AND [embase]/lim \\
\hline \#30 & “"Transplantations, Stem Cell” AND [humans]/lim AND [embase]/lim \\
\hline \#31 & “"Transplantation, Stem Cell” AND [humans]/lim AND [embase]/lim \\
\hline$\# 32$ & “Transplantation, Hematopoietic Stem Cell” AND [humans]/lim AND [embase]/lim \\
\hline \#33 & “Stem Cell Transplantation, Hematopoietic” AND [humans]/lim AND [embase]/lim \\
\hline \#34 & “Bone Marrow Transplantation" AND [humans]/lim AND [embase]/lim \\
\hline$\# 35$ & “"Bone Marrow Purging” AND [humans]/lim AND [embase]/lim \\
\hline \#36 & “"Hematopoietic Stem Cell Mobilization” AND [humans]/lim AND [embase]/lim \\
\hline \#37 & "Progenitor Cells, Hematopoietic" AND [humans]/lim AND [embase]/lim \\
\hline \#38 & “"Hematopoietic Progenitor Cells” AND [humans]/lim AND [embase]/lim \\
\hline
\end{tabular}




\begin{tabular}{|l|l|}
\hline$\# 39$ & Cell, Hematopoietic Progenitor AND [humans]/lim AND [embase]/lim \\
\hline$\# 40$ & “Cells, Hematopoietic Progenitor” AND [humans]/lim AND [embase]/lim \\
\hline$\# 41$ & "Hematopoietic Progenitor Cell” AND [humans]/lim AND [embase]/lim \\
\hline$\# 42$ & "Progenitor Cell, Hematopoietic” AND [humans]/lim AND [embase]/lim \\
\hline$\# 43$ & “Stem Cells, Hematopoietic” AND [humans]/lim AND [embase]/lim \\
\hline$\# 45$ & “Cell, Hematopoietic Stem” AND [humans]/lim AND [embase]/lim \\
\hline$\# 46$ & “Cells, Hematopoietic Stem” AND [humans]/lim AND [embase]/lim \\
\hline$\# 47$ & “Stem Cell Mobilization” AND [humans]/lim AND [embase]/lim \\
\hline$\# 48$ & “Benign Neoplasms” AND [humans]/lim AND [embase]/lim \\
\hline$\# 49$ & \#28 OR \#29 OR \#30 OR \#31 OR \#32 OR \#33 OR \#34 OR \#35 OR \#36 OR \#37 OR \#38 OR \#39 OR \#40 OR \#41 OR \#42 \\
\hline$\# 50$ & OR \#43 OR \#44 OR \#45 OR \#46 OR \#47 OR \#48 \\
\hline$\# 51$ & valid* AND [embase]/lim \\
\hline$\# 52$ & “cross cultural” AND [humans]/lim AND [embase]/lim \\
\hline$\# 53$ & “cross cultural adaptation” AND [embase]/lim \\
\hline$\# 54$ & version AND [embase]/lim \\
\hline$\# 55$ & “cross-cultural adaptation” AND [embase]/lim \\
\hline$\# 56$ & $\# 50$ OR \#51 OR \#52 OR \#53 OR \#54 OR \#55 \\
\hline$\# 57$ & $\# 19$ AND \#27 AND \#49 AND \#56 \\
\hline
\end{tabular}

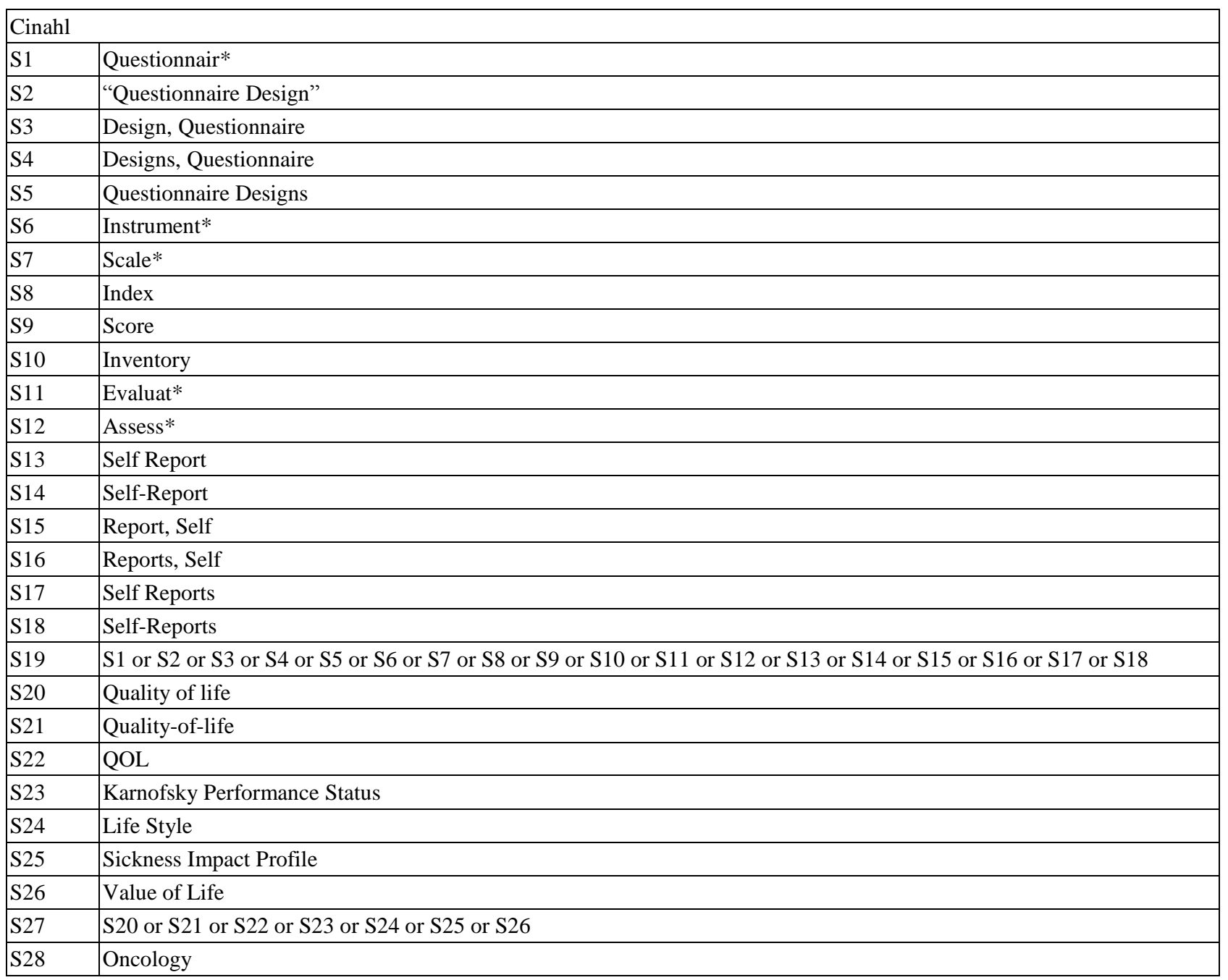



Measurement of the FACT-BMT Questionnaire

\begin{tabular}{|c|c|}
\hline S29 & Stem Cell Transplantations \\
\hline S30 & Transplantations, Stem Cell \\
\hline S31 & Transplantation, Stem Cell \\
\hline S32 & Transplantation, Hematopoietic Stem Cell \\
\hline S33 & Stem Cell Transplantation, Hematopoietic \\
\hline S34 & Bone Marrow Transplantation \\
\hline S35 & Bone Marrow Purging \\
\hline S36 & Hematopoietic Stem Cell Mobilization \\
\hline S37 & Progenitor Cells, Hematopoietic \\
\hline S38 & Hematopoietic Progenitor Cells \\
\hline S39 & Hematopoietic Progenitor Cells \\
\hline S40 & Cells, Hematopoietic Progenitor \\
\hline S41 & Hematopoietic Progenitor Cell \\
\hline S42 & Progenitor Cell, Hematopoietic \\
\hline S43 & Stem Cells, Hematopoietic \\
\hline S44 & Cell, Hematopoietic Stem \\
\hline S45 & Cell, Hematopoietic Stem \\
\hline S46 & Stem Cell Mobilization \\
\hline S47 & Cells, Hematopoietic Stem \\
\hline S48 & Benign Neoplasms \\
\hline S49 & Transplantation, BoneMarrow \\
\hline S50 & HematopoieticStemCellTransplantation \\
\hline S51 & Grafting, BoneMarrow \\
\hline S52 & BoneMarrowGrafting \\
\hline S53 & BoneMarrowCellTransplantation \\
\hline S54 & $\begin{array}{l}\text { S28 or S29 or S30 or S31 or S32 or S33 or S34 or S35 or S36 or S37 or S38 or S39 or S40 or S41 or S42 or S43 or S44 or S45 } \\
\text { or S46 or S47 or S48 or S49 or S50 or S51 or S52 or S53 }\end{array}$ \\
\hline S55 & S19 and S27 and S54 \\
\hline S56 & valid* \\
\hline S57 & translat* \\
\hline S58 & cross cultural \\
\hline S59 & cross-cultural \\
\hline S60 & cross cultural adapt* \\
\hline S61 & cross-cultural adapt* \\
\hline S62 & version \\
\hline S63 & S56 or S57 or S58 or S59 or S60 or S61 or S62 \\
\hline S64 & S55 and S63 \\
\hline \multicolumn{2}{|c|}{ SCIELO } \\
\hline 1 & Qualidade de vida AND FACT-BMT AND questionário \\
\hline
\end{tabular}

